\title{
A SUBSTITUTE NAME FOR THE EXTINCT GENUS EORICANIA HAUPT \\ [HEMIPTERA: HOMOPTERA: RICANIIDAE]
}

\author{
By Frank M. Carpenter \\ Museum of Comparative Zoology, Harvard University, \\ Cambridge, Mass. 02138
}

In 1956 Dr. Hermann Haupt described a fossil homopteron for which he named a new genus, Eoricania, in the family Ricaniidae. Several years ago, while preparing a catalogue of fossil Homoptera, I noticed that his generic name was preoccupied by Eoricania Henriksen (1922) in the same family. I accordingly wrote to Dr. Haupt in 1985 , calling his attention to the homonymy. Since I have received no reply and have not seen a publication of a substitute name, I now propose the following replacement:

Neoricania, nomen novum, pro Eoricania Haupt, 1956, p. 12, non Eoricania Henriksen, 1922. The type species, Eoricania reticulata Haupt, 1956, original designation, becomes Neoricania reticulata (Haupt), new combination. The new generic name is derived from ricania, with the addition of the prefix, eo. The genus is known only from the Eocene of Germany.

\section{REFERENCES}

HAUPT, HermanN

1956. Betraeg zur Kenntnis der eozanen Arthropodenfauna des Geiseltales: Nova Acta Leopoldina, v. 18, no. 128, pp. 1-96.

HeNRIKSEN, K. L.

1956. Eocene insects of Denmark: Danmarks Geologiske Undersoegelse, v. 2, no. 37, pp. 1-36. 

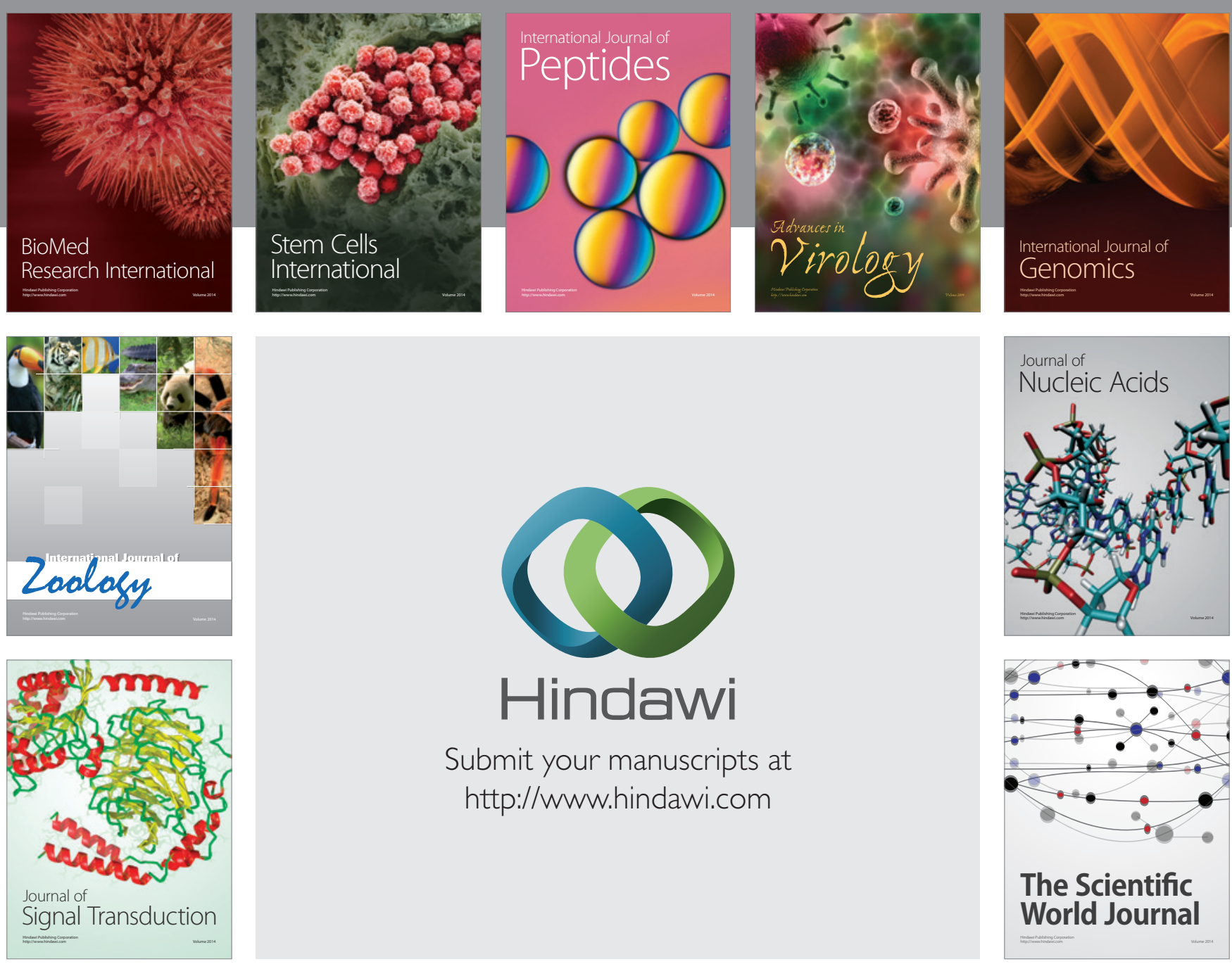

Submit your manuscripts at

http://www.hindawi.com
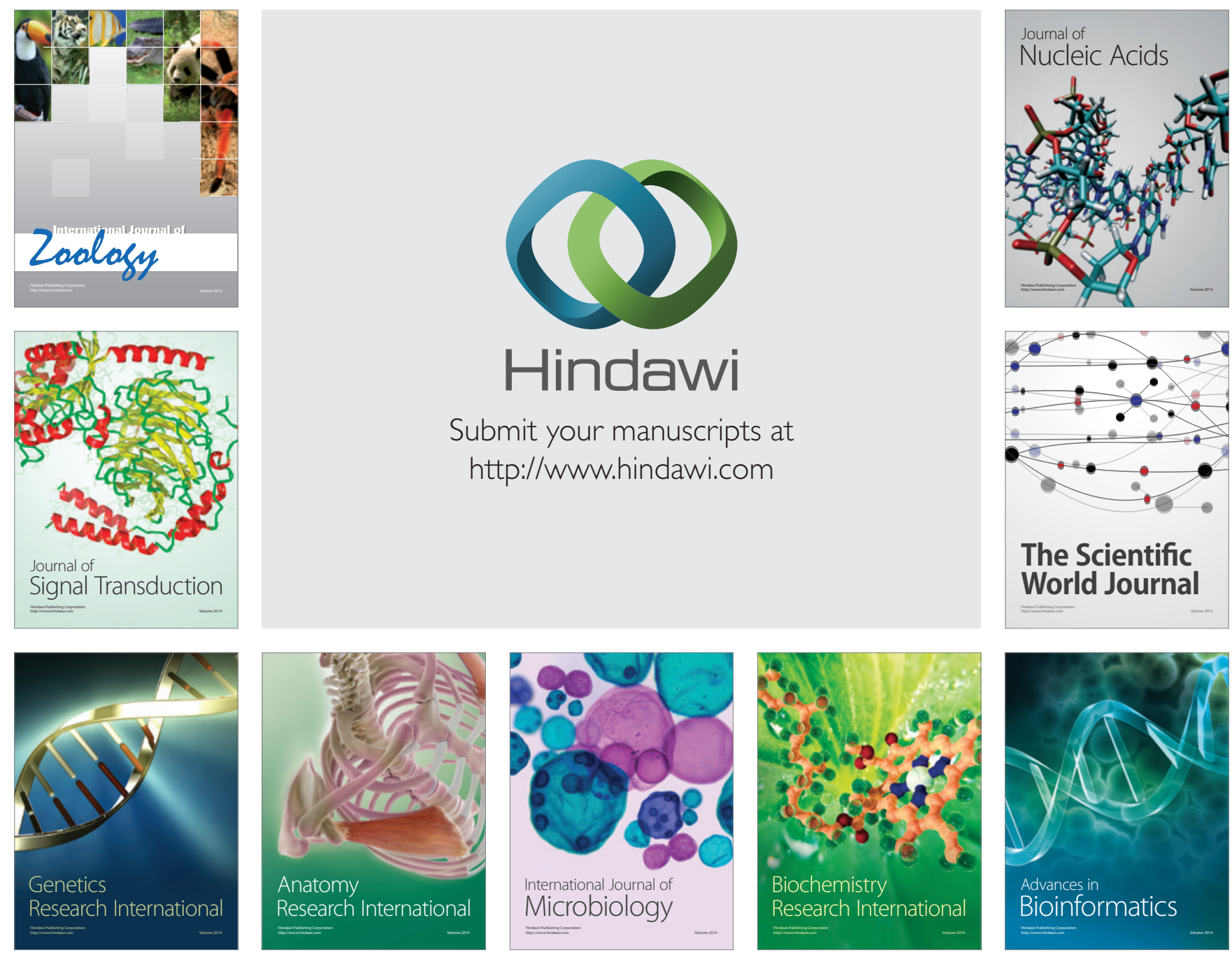

The Scientific World Journal
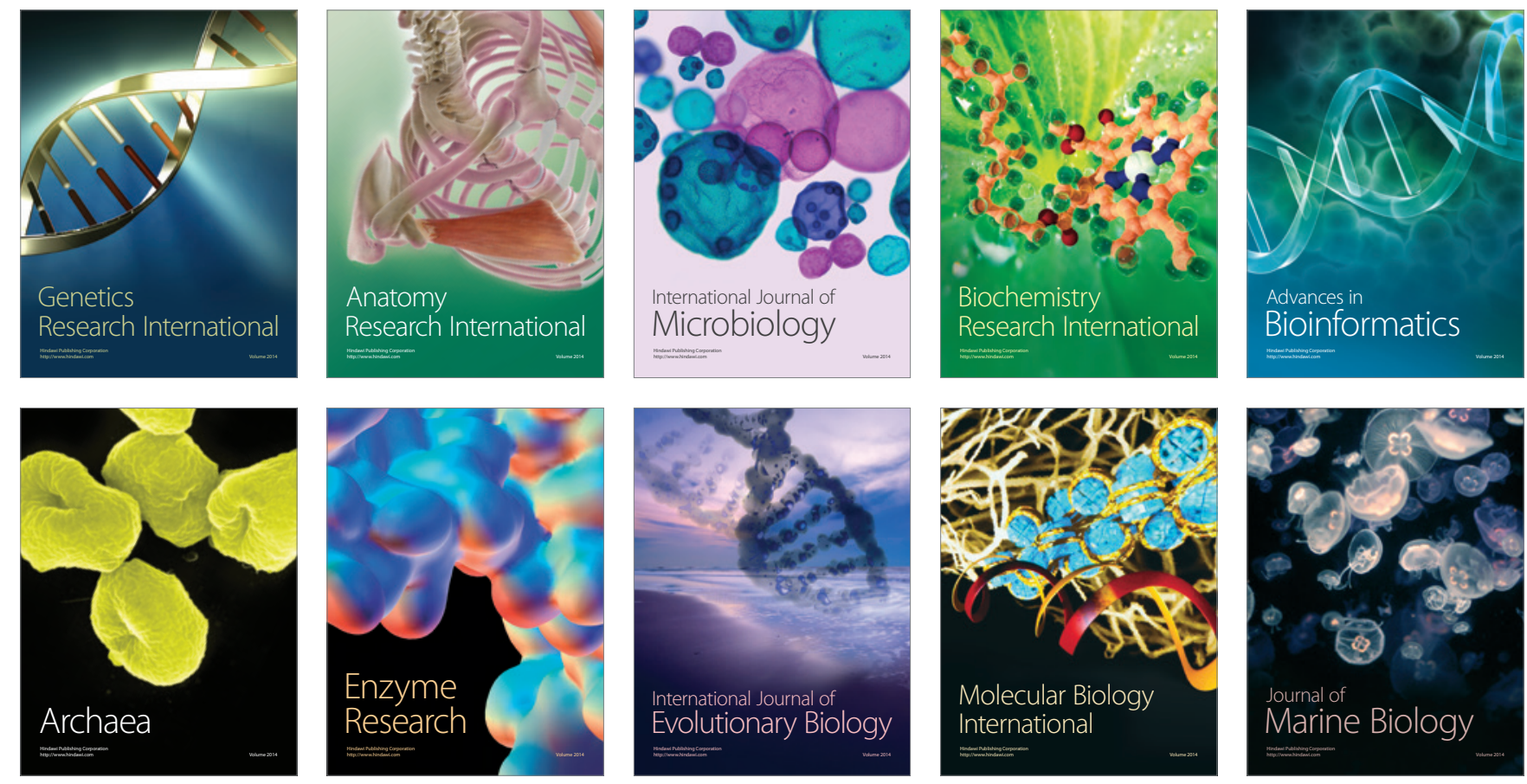